\title{
Lactobacillus gasseri requires peptides, not proteins or free amino acids, for growth in milk
}

\author{
K. Arakawa, ${ }^{*}$ K. Matsunaga, ${ }^{*}$ S. Takihiro, ${ }^{*}$ A. Moritoki, ${ }^{*}$ S. Ryuto, ${ }^{*}$ Y. Kawai, $\dagger$ T. Masuda, $\dagger$ and T. Miyamoto ${ }^{* 1}$ \\ ${ }^{*}$ Graduate School of Environmental and Life Science, Okayama University, Okayama 7008530, Japan \\ †Graduate School of Bioresource Sciences, Nihon University, Kanagawa 2520880, Japan
}

\begin{abstract}
Lactobacillus gasseri is a widespread commensal lactic acid bacterium inhabiting human mucosal niches and has many beneficial effects as a probiotic. However, L. gasseri is difficult to grow in milk, which hurts usability for the food industry. It had been previously reported that supplementation with yeast extract or proteose peptone, including peptides, enables L. gasseri to grow well in milk. In this study, our objective was to confirm peptide requirement of $L$. gasseri and evaluate efficacy of peptide release by enzymatic proteolysis on growth of $L$. gassei in milk. Three strains of $L$. gasseri did not grow well in modified DeMan, Rogosa, Sharpe broth without any nitrogen sources (MRS-N), but addition of a casein-derived peptide mixture, tryptone, promoted growth. In contrast, little effect was observed after adding casein or a casein-derived amino acid mixture, casamino acids. These results indicate that $L$. gasseri requires peptides, not proteins or free amino acids, among milk-derived nitrogen sources for growth. Lactobacillus gasseri JCM $1131^{\mathrm{T}}$ hardly had growth capacity in 6 kinds of milk-based media: bovine milk, human milk, skim milk, cheese whey, modified MRS-N (MRSL-N) supplemented with acid whey, and MRSL-N supplemented with casein. Moreover, treatment with digestive proteases, particularly pepsin, to release peptides made it grow well in each milk-based medium. The pepsin treatment was the most effective for growth of strain JCM $1131^{\mathrm{T}}$ in skim milk among the tested foodgrade proteases such as trypsin, $\alpha$-chymotrypsin, calf rennet, ficin, bromelain, and papain. As well as strain JCM $1131^{\mathrm{T}}$, pepsinolysis of milk improved growth of other L. gasseri strains and some strains of enteric lactobacilli such as Lactobacillus crispatus, Lactobacillus gallinarum, Lactobacillus johnsonii, and Lactobacillus reuteri. These results suggest that some relatives of $L$. gasseri also use peptides as desirable nitrogen sources, and that milk may be a good supplier of nutritious
\end{abstract}

Received September 15, 2014

Accepted November 2, 2014.

${ }^{1}$ Corresponding author: tmnono@cc.okayama-u.ac.jp peptides to enteric lactobacilli including L. gasseri after peptic digestion in the gastrointestinal tract. This is the first report showing peptide requirement of L. gasseri and efficacy of pepsinolysis on the growth of L. gasseri and its relatives in milk. This study would contribute to increasing usability of L. gasseri and its relatives as probiotics in dairy foods.

Key words: Lactobacillus gasseri, peptide requirement, proteolysis, pepsin

\section{INTRODUCTION}

Lactobacilli are generally recognized as important beneficial members of the gastrointestinal (GI) microbiota of human and animals, along with bifidobacteria. Among them, Lactobacillus gasseri has been frequently detected in the GI tract and feces of humans (Selle and Klaenhammer, 2013), and were once reported as a predominant species of lactic acid bacteria (LAB) in the human small bowel (Reuter, 2001). Colonization of the human GI tract by L. gasseri has been often observed to be established at an early stage of life and to last throughout adulthood (Wall et al., 2007). Because $L$. gasseri is one of the predominant LAB species in the oral and the vaginal cavities and on the mammary areola of humans, it is presumed to be partly transferred to the GI tract through the oral cavity of neonates from the vaginal tract and the mammary areola of their mothers during delivery and lactation (Matsumiya et al., 2002; Martín et al., 2003; Dal Bello and Hertel, 2006; Lamont et al., 2011).

As for the beneficial effects of oral administration of L. gasseri upon the host, many researchers have reported maintenance of gut homeostasis, regulation of immune system, reduction of allergic symptoms, prevention of bacterial and viral infections, and alleviation of infectious disease symptoms (Selle and Klaenhammer, 2013). Recently, it has been also revealed that $L$. gasseri SBT2055 has a clear antiobesity effect for humans (Kadooka et al., 2010). The greater part of these benefits should be derived by survival and transient colonization of the commensal LAB in the GI tract. The viability and the colonization ability of many $L$. gasseri strains have been already confirmed on in vitro 
and in vivo assays, and are regarded as depending on acid tolerance, bile resistance, adhesion capacity to the GI epithelial and mucus layers, metabolic capacity and several host-dependent factors such as core temperature, nutritional environment, and immune system (Azcarate-Peril et al., 2008; Selle and Klaenhammer, 2013). In anticipation of such beneficial effects, several fermented food products and dietary supplements using $L$. gasseri as a probiotic are widely developed and distributed by food companies.

Apart from that, some strains of $L$. gasseri have been reported to produce antibacterial peptides, namely bacteriocins. Lactobacillus gasseri LA39 (JCM 11657) produces a circular bacteriocin, gassericin $\mathrm{A}$, linked at the N- and C-terminal ends (Kawai et al., 1998; Arakawa et al., 2010). Lactobacillus gasseri SBT2055 and LA158 (JCM 11046) produce the same 2-component bacteriocin, gassericin $\mathrm{T}$, that is highly similar to acidocin LF221 and gassericin K7 from L. gasseri LF221 and K7, respectively (Kawai et al., 2000; Majhenic et al., 2004; Treven et al., 2013; Yasuta et al., 2014). These bacteriocins are heat-stable and $\mathrm{pH}$-tolerant and have broad-spectral antibacterial activity against various strains of LAB and food-spoilage and pathogenic bacteria including Bacillus cereus, Listeria monocytogenes, and Staphylococcus aureus; and therefore, they and their producers are expected to be used for safe food preservation (Toba et al., 1991; Itoh et al., 1995; Kawai et al., 1997; Bogovic-Matijasić et al., 1998; Bogovic-Matijasić and Rogelj, 2000). Indeed, the gassericin A-containing culture supernatant of L. gasseri LA39 and its concentrate have been effectively used as biopreservatives on custard cream manufacturing (Arakawa et al., 2009; Nakamura et al., 2013).

Thus, L. gasseri strains are considered to be live materials useful as probiotics or biopreservatives in the food industry. However, it is empirically demonstrated that L. gasseri cannot grow well in milk without any supplement, despite the good growth in semisynthetic media such as de Man, Rogosa and Sharpe (MRS) broth and Lactobacillus Selection broth. The poor growth in milk has also been observed with some strains of the other relative lactobacilli: Lactobacillus acidophilus, Lactobacillus gallinarum, and Lactobacillus johnsonii (Elli et al., 1999; Masuda et al., 2003a,b; Avonts et al., 2004). We previously showed that L. gasseri successfully grew in milk-based media by supplementation with yeast extract or proteose peptone that are components of MRS broth, not free amino acids, nucleotides, glucose, minerals, or vitamins (Arakawa et al., 2008). Avonts et al. (2004) had also reported that addition of yeast extract into milk-based media is effective on growth of $L$. acidophilus and L. johnsonii strains as well as $L$. gasseri. These findings suggest that L. gasseri and the relatives would require peptides as nitrogen sources in milk-based media. In this study, we confirmed peptide requirements of $L$. gasseri and evaluated efficacy of proteolysis, particularly using pepsin, of milk proteins on growth of $L$. gasseri in milk-based media. In addition, the growth-promoting effect of pepsinolysis of milk was examined in strains of the L. acidophilus complex members including L. acidophilus, Lactobacillus crispatus, Lactobacillus amylovorus, L. gallinarum, L. gasseri, and L. johnsonii (Johnson et al., 1980; Fujisawa et al., 1992), and other lactobacilli.

\section{MATERIALS AND METHODS}

\section{Bacterial Strains}

Lactobacillus strains used in this study were listed in Table 1. All strains were precultured 3 times with a $1 \%$ (vol/vol) inoculum at $37^{\circ} \mathrm{C}$ for $24 \mathrm{~h}$ in lactobacilli MRS broth (Oxoid, Basingstoke, UK). The MRS broth was autoclaved at $121^{\circ} \mathrm{C}$ for $15 \mathrm{~min}$.

\section{Determination of Nitrogen Sources Required by L. gasseri}

Lactobacillus gasseri JCM $1131^{\mathrm{T}}$, JCM 11046, and JCM 11657 were cultivated with a 1\% (vol/vol) inoculum at $37^{\circ} \mathrm{C}$ for 48 or $72 \mathrm{~h}$ in modified MRS broth (MRS-N) without peptone, beef extract (Lab-Lemco), and yeast extract, and $8.3 \%(\mathrm{wt} / \mathrm{vol}$ ) reconstituted skim milk (protein content 3.0\%, RSM; Megmilk Snow Brand, Hokkaido, Japan) supplemented with casein (Nacalai Tesque, Kyoto, Japan), tryptone (casein enzymatic hydrolysates, peptide mixture; Becton Dickinson, Franklin Lakes, NJ), or casamino acids (casein acid hydrolysates, free amino acid mixture; Becton Dickinson). Casein, tryptone, and casamino acids were added at $3.0 \%$ (wt/vol) each to MRS-N and 1.0 or $3.0 \%$ (wt/ vol) each to RSM. The MRS-N-based media were autoclaved at $121^{\circ} \mathrm{C}$ for $15 \mathrm{~min}$. The RSM-based media were autoclaved at $110^{\circ} \mathrm{C}$ for $20 \mathrm{~min}$. Cell growth was monitored with $\mathrm{pH}$ and optical density (OD) at 620 $\mathrm{nm}$ (in the case of the MRS-N-based media) or titratable acidity (in the case of the RSM-based media) of culture solutions. Results given are mean values of at least 2 independent determinations.

\section{Effect of Digestive Proteases on Growth of L. gasseri in Milk-Based Media}

Lactobacillus gasseri JCM $1131^{\mathrm{T}}$ was cultivated with a $1 \%$ (vol/vol) inoculum at $37^{\circ} \mathrm{C}$ for $72 \mathrm{~h}$ in whole bovine milk (WBM), human breast milk (HBM), RSM, 21.5\% (wt/vol) reconstituted cheese whey (pro- 
Table 1. Bacterial stains used in this study

\begin{tabular}{|c|c|c|}
\hline Species & Strain & Source $^{1}$ \\
\hline \multirow[t]{4}{*}{ Lactobacillus acidophilus } & JCM $1132^{\mathrm{T}}$ & $\mathrm{JCM}$ \\
\hline & NIAI L-54 & NIAI \\
\hline & 305501 & Our laboratory \\
\hline & 306704 & Our laboratory \\
\hline Lactobacillus amylovorus & JCM $1126^{\mathrm{T}}$ & JCM \\
\hline Lactobacillus crispatus & $\mathrm{JCM} 1185^{\mathrm{T}}$ & JCM \\
\hline Lactobacillus gallinarum & JCM $2011^{\mathrm{T}}$ & JCM \\
\hline \multirow[t]{5}{*}{ Lactobacillus gasseri } & $\mathrm{JCM} 1131^{\mathrm{T}}$ & $\mathrm{JCM}$ \\
\hline & JCM 1025 & $\mathrm{JCM}$ \\
\hline & JCM 1130 & JCM \\
\hline & JCM 11046 & JCM \\
\hline & JCM 11657 & JCM \\
\hline Lactobacillus johnsonii & JCM $2012^{\mathrm{T}}$ & $\mathrm{JCM}$ \\
\hline \multirow[t]{2}{*}{ Lactobacillus delbrueckii ssp. bulgaricus } & JCM $1002^{\mathrm{T}}$ & $\mathrm{JCM}$ \\
\hline & 7235 & Our laboratory \\
\hline Lactobacillus delbrueckii ssp. delbrueckii & ATCC $9649^{\mathrm{T}}$ & ATCC \\
\hline \multirow[t]{3}{*}{ Lactobacillus delbrueckii ssp. lactis } & $\mathrm{JCM} 1248^{\mathrm{T}}$ & JCM \\
\hline & 1135 & Our laboratory \\
\hline & 306701 & Our laboratory \\
\hline Lactobacillus reuteri & $\mathrm{JCM} 1112^{\mathrm{T}}$ & JCM \\
\hline Lactobacillus fermentum & $\mathrm{JCM} 1173^{\mathrm{T}}$ & JCM \\
\hline Lactobacillus oris & JCM $11028^{\mathrm{T}}$ & JCM \\
\hline Lactobacillus vaginalis & $\mathrm{JCM} 9505^{\mathrm{T}}$ & $\mathrm{JCM}$ \\
\hline \multirow{5}{*}{ Lactobacillus casei } & ATCC $393^{\mathrm{T}}$ & ATCC \\
\hline & KCTC 3260 & KCTC \\
\hline & JCM 11302 & $\mathrm{JCM}$ \\
\hline & NIAI L-14 & NIAI \\
\hline & L-49 & Our laboratory \\
\hline \multirow{5}{*}{ Lactobacillus paracasei ssp. paracasei } & NBRC $15889^{\mathrm{T}}$ & NBRC \\
\hline & ATCC 25598 & ATCC \\
\hline & S-3-1 & Our laboratory \\
\hline & 34143 & Our laboratory \\
\hline & $34143 \mathrm{~S}$ & Our laboratory \\
\hline Lactobacillus rhamnosus & $\mathrm{JCM} 1136^{\mathrm{T}}$ & JCM \\
\hline Lactobacillus salivarius & JCM $1231^{\mathrm{T}}$ & $\mathrm{JCM}$ \\
\hline \multirow[t]{3}{*}{ Lactobacillus brevis } & NBRC $107147^{\mathrm{T}}$ & NBRC \\
\hline & 1056 & Our laboratory \\
\hline & CMA & Our laboratory \\
\hline \multirow[t]{5}{*}{ Lactobacillus plantarum ssp. plantarum } & $\mathrm{JCM} 1149^{\mathrm{T}}$ & JCM \\
\hline & IFO 3070 & IFO \\
\hline & 301102 & Our laboratory \\
\hline & $301102 \mathrm{~S}$ & Our laboratory \\
\hline & 6214 & Our laboratory \\
\hline
\end{tabular}

${ }^{1}$ ATCC $=$ American Type Culture Collection; IFO = Institute for Fermentation, Osaka, Japan; JCM = Japan Collection of Microorganisms; KCTC $=$ Korean Collection for Type Cultures; NBRC = National Biological Resources Center, Japan; NIAI = National Institute of Animal Industry, Japan.

tein content 3.0\%, RCW, Megmilk Snow Brand), an acid whey medium (protein content 1.5\%, AWM), and a casein medium $(\mathbf{C M})$ with or without digestive protease treatments. Protein content in the milk-based media was measured with the conventional Lowry method using bovine serum albumin as a control. The HBM was provided with informed consent by a healthy volunteer in the lactation period. Acid whey powder was prepared by lyophilizing the dialyzate of the supernatant centrifugally separated $\left(2,500 \times g\right.$, at $4^{\circ} \mathrm{C}$ for $20 \mathrm{~min}$ ) after isoelectric precipitation of RSM at pH 4.6 (adjusted with $6 \mathrm{~N} \mathrm{HCl}$ ). Before the dialysis, the supernatant was filtered through a no. 2 filter paper (Toyo Roshi Kaisha, Tokyo, Japan). The dialysis was performed at $4^{\circ} \mathrm{C}$ for $48 \mathrm{~h}$ against distilled water using a $12 \mathrm{kDa}$ cut-off membrane (Eidia, Tokyo, Japan). The AWM was prepared by adding the acid whey powder to modified MRS-N (MRSL-N) where $2.0 \%$ (wt/vol) lactose replaced glucose. The CM was prepared by mixing $3.0 \%$ (wt/vol) casein with MRSL-N. In the digestive protease treatments, pepsin (Sigma-Aldrich, St. Louis, MO), trypsin (Wako Pure Chemical, Osaka, Japan), and $\alpha$-chymotrypsin (Nacalai Tesque) were used. The treatment with trypsin and $\alpha$-chymotrypsin was jointly performed after the pepsin treatment. Each treatment condition was shown in Table 2. All milk-based media were adjusted to $\mathrm{pH} 7.0$ with $6 \mathrm{~N} \mathrm{NaOH}$, and then autoclaved at $110^{\circ} \mathrm{C}$ for 20 min for sterilization and inactivation of the proteases. Cell growth was monitored with $\mathrm{pH}$ and titratable acidity of the culture solutions. 
Table 2. Reaction conditions on protease treatments

\begin{tabular}{lccccc}
\hline & & & \multicolumn{3}{c}{ Condition } \\
\cline { 4 - 6 } Enzyme & $\begin{array}{c}\text { Titer } \\
(\mathrm{U} / \mathrm{mg})\end{array}$ & $\begin{array}{c}\text { Amount used } \\
(\mathrm{mg} / 100 \mathrm{~mL})\end{array}$ & $\mathrm{pH}$ & $\begin{array}{c}\text { Temperature } \\
\left({ }^{\circ} \mathrm{C}\right)\end{array}$ & $\begin{array}{c}\text { Time } \\
(\mathrm{h})\end{array}$ \\
\hline Pepsin & 800 & 200 & 2.0 & 37 & 1.0 \\
Trypsin & 30 & 150 & 7.0 & 37 & 2.5 \\
--Chymotrypsin & 66 & 100 & 7.0 & 37 & 2.5 \\
Rennet & - & 2 & 5.5 & 35 & 1.0 \\
Ficin & 650 & 50 & 6.0 & 40 & 1.5 \\
Bromelain & 500 & 350 & 7.0 & 45 & 1.0 \\
Papain & 1,300 & 150 & 5.0 & 45 & 1.0 \\
\hline
\end{tabular}

As a control, $\mathrm{pH}$ and titratable acidity of the culture solutions of strain JCM $1131^{\mathrm{T}}$ cultivated in peptide-free MRSL-N with the digestive protease treatment were measured. Results given are mean values of 3 independent determinations.

\section{Effect of Food-Grade Proteases on Growth of L. gasseri in Skim Milk}

Lactobacillus gasseri $\mathrm{JCM} 1131^{\mathrm{T}}$ was cultivated with a $1 \%$ (vol/vol) inoculum at $37^{\circ} \mathrm{C}$ for $72 \mathrm{~h}$ in RSM with or without food-grade protease treatments. In the treatments, pepsin, trypsin, $\alpha$-chymotrypsin, calf rennet (Casa Nord, Hokkaido, Japan), ficin (Tokyo Chemical, Tokyo, Japan), bromelain (Godo Shusei, Tokyo, Japan), and papain (Godo Shusei) were used. Each treatment condition was shown in Table 2. All milk-based media were adjusted to $\mathrm{pH} 7.0$ with $6 \mathrm{~N} \mathrm{NaOH}$, and then autoclaved at $110^{\circ} \mathrm{C}$ for $20 \mathrm{~min}$. Cell growth was monitored with $\mathrm{pH}$, titratable acidity, and viable cell count of the culture solutions. The MRS agar (Oxoid) was used to count the viable cells. As a control, $\mathrm{pH}$ and viable cell count of the culture solutions of strain JCM $1131^{\mathrm{T}}$ cultivated in MRS broth were measured. Results given are mean values of 3 independent determinations.

\section{Effect of Pepsinolysis on Growth of 43 Lactobacillus Strains in Milk}

To determine the effect of pepsinolysis, 43 Lactobacillus strains listed in Table 1 were cultivated with a $1 \%$ (vol/vol) inoculum at $37^{\circ} \mathrm{C}$ for $72 \mathrm{~h}$ in WBM with or without the pepsin treatment. The pepsinolysis condition was the same as above. All media were adjusted to pH 7.0 with $6 \mathrm{~N} \mathrm{NaOH}$, and then autoclaved at $110^{\circ} \mathrm{C}$ for $20 \mathrm{~min}$. Cell growth was evaluated with decreases in culture $\mathrm{pH}$ for 24,48 , and $72 \mathrm{~h}$ of incubation. Results given are mean values of at least 2 independent determinations.

\section{RESULTS}

\section{Confirmation of Peptide Requirement of L. gasseri}

Lactobacillus gasseri JCM $1131^{\mathrm{T}}$, JCM 11046, and JCM 11657 were cultivated in MRS broth, MRS-N, and modified MRS-N media supplemented with casein, tryptone, or casamino acids. Throughout $48 \mathrm{~h}$ of incubation, $\mathrm{pH}$ value and turbidity of the culture solutions of the 3 strains in the casein- or casamino acids-added MRS-N media were almost unchanged as well as those in MRS-N (Supplemental Figure S1, http://dx.doi. org $/ 10.3168 /$ jds.2014-8860, and Figure 1). In contrast, the addition of tryptone to MRS-N resulted in good growth of the 3 strains with decreasing $\mathrm{pH}$ value $(\mathrm{pH}$ 3.8-4.3 at $48 \mathrm{~h}$ incubation) and increasing turbidity $\left(\mathrm{OD}_{620}=1.2-2.2\right.$ at $48 \mathrm{~h}$ incubation $)$ of the culture solutions, although the growth in the tryptone-added MRS-N was inferior, particularly with strain JCM 11657 , to that in MRS broth (pH 3.6-4.0 and $\mathrm{OD}_{620}=$ $1.9-2.7$ at $48 \mathrm{~h}$ incubation).

Next, the 3 strains were cultivated in RSM and modified RSM media supplemented with casein, tryptone, or casamino acids. Similar to in the MRS-N-based media, the addition of casein and casamino acids to RSM hardly had any effects, whereas $1 \%$ tryptone promoted the growth of strains JCM $1131^{\mathrm{T}}$ and JCM 11046 with decreasing $\mathrm{pH}$ value ( $\mathrm{pH} 3.7$ at $48 \mathrm{~h}$ incubation) and increasing titratable acidity $(1.3-1.4 \%$ at $48 \mathrm{~h}$ incubation) of the culture solutions (Supplemental Figure S2, http://dx.doi.org/10.3168/jds.2014-8860, and Figure 2 ). In the case of strain JCM 11657, the effect of $1 \%$ tryptone was limited ( $\mathrm{pH} 4.8$ and $0.7 \%$ acidity at $48 \mathrm{~h}$ incubation) but $3 \%$ was enough to enhance the growth (pH 4.1 and $1.4 \%$ acidity at $48 \mathrm{~h}$ incubation).

These results indicate that the $L$. gasseri strains required tryptone (peptides), not casein (proteins) or casamino acids (free amino acids), among milk-derived nitrogen sources for their growth. 
A

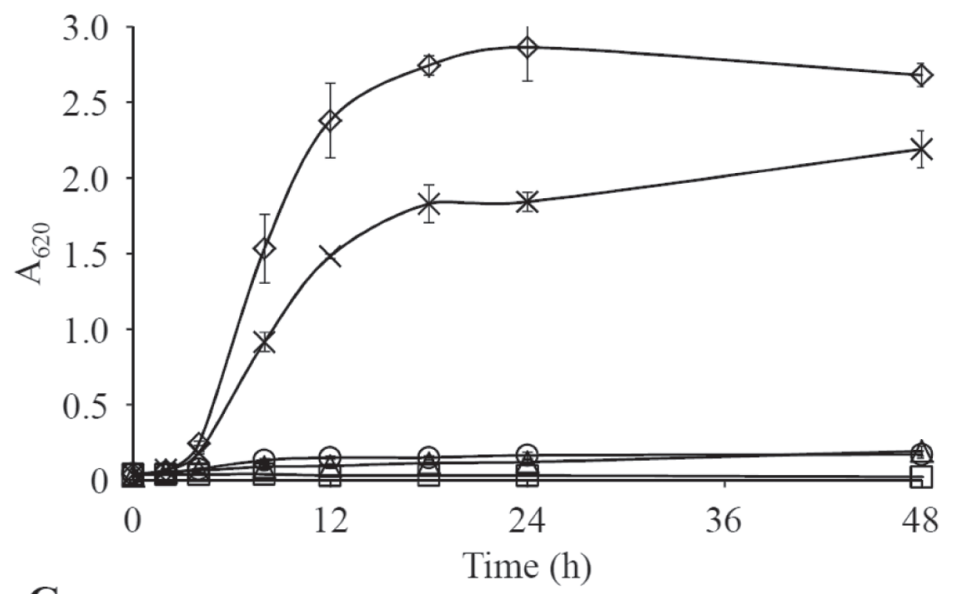

B

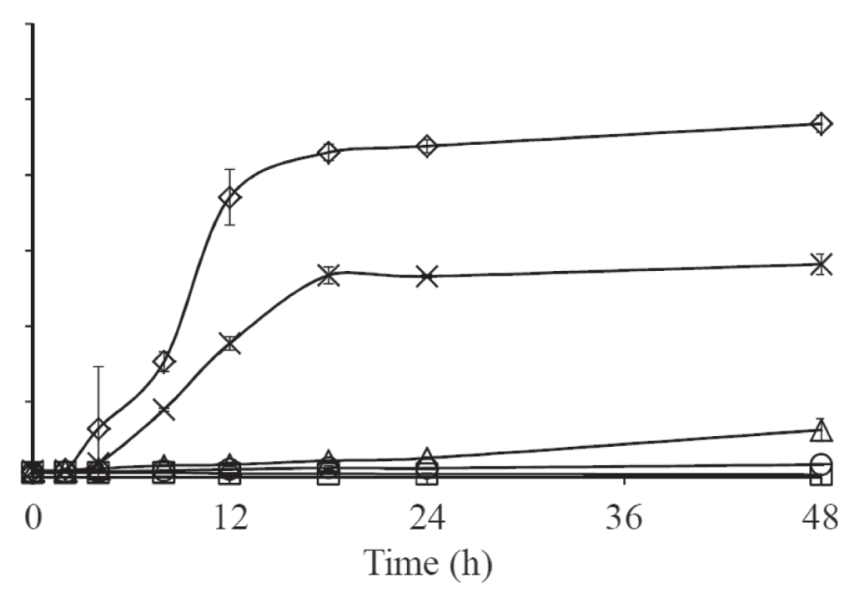

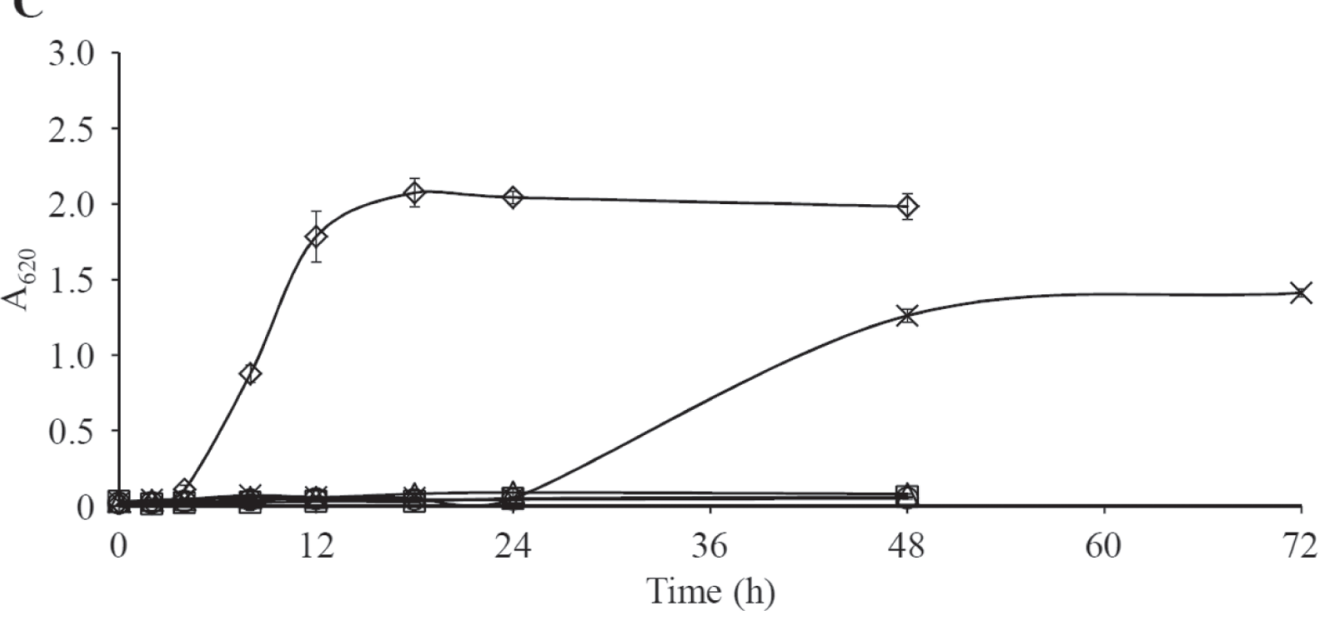

Figure 1. Changes in turbidity measured at optical density at $620 \mathrm{~nm}\left(\mathrm{OD}_{620}\right)$ of culture solutions of Lactobacillus gasseri JCM $1131^{\mathrm{T}}$ (A), JCM 11046 (B), and JCM 11657 (C) in DeMan, Rogosa, Sharpe (MRS)-based media with casein, tryptone, or casamino acids as nitrogen sources. $\diamond=$ MRS broth; $\square=$ modified MRS broth (MRS-N) without peptone, Lab-Lemco, and yeast extract; $\Delta=$ MRS-N supplemented with $3.0 \%$ (wt/vol) casein; $x=$ MRS-N supplemented with $3.0 \%$ (wt/vol) tryptone; $\bigcirc=$ MRS-N supplemented with $3.0 \%$ (wt $/$ vol) casamino acids Results are means of 3 independent determinations. Error bars represent standard deviations.

\section{Effect of Digestive Proteases on Growth of L. gasseri in Milk-Based Media}

Peptide requirement of a $L$. gasseri strain, JCM $1131^{\mathrm{T}}$, was examined also using 6 kinds of milk-based media (WBM, HBM, RSM, RCW, AWM, and CM) treated with digestive proteases (pepsin, trypsin, and $\alpha$-chymotrypsin). In all of the tested milk-based media regardless of what sort of protein included, the pepsin treatment drastically promoted the growth of strain JCM $1131^{\mathrm{T}}$ with decreasing $\mathrm{pH}$ value $(\mathrm{pH} 3.4-4.5$ at 48 incubation) and increasing titratable acidity $(0.8-1.5 \%$ at $48 \mathrm{~h}$ incubation) of the culture solutions (Supplemental Figure S3, http://dx.doi.org/10.3168/jds.20148860, and Figure 3). Effect of the joint treatment with trypsin and $\alpha$-chymotrypsin following the pepsin treatment was not so high $(\mathrm{pH} 3.7-4.2$ and $0.6-1.6 \%$ acidity at $48 \mathrm{~h}$ incubation). On the contrary, the joint treatment slightly reduced the effect of the pepsin treatment alone in HBM ( $\mathrm{pH} 3.7$ and $0.7 \%$ acidity from $\mathrm{pH} 3.4$ and $0.8 \%$ acidity at $48 \mathrm{~h}$ incubation). Lactobacillus gasseri JCM $1131^{\mathrm{T}}$ hardly grew in peptide-free MRSL-N treated with the digestive proteases as well as in all undigested milk-based media. These results show that the growth-promoting effect was due to milk-derived peptides released by the digestive proteases, not the proteases themselves.

\section{Effect of Food-Grade Proteases on Growth of L. gasseri in Skim Milk}

Growth-promoting effect of peptide release by several food-grade proteases (pepsin, trypsin, $\alpha$-chymotrypsin, calf rennet, ficin, bromelain, and papain) was evaluated 
A

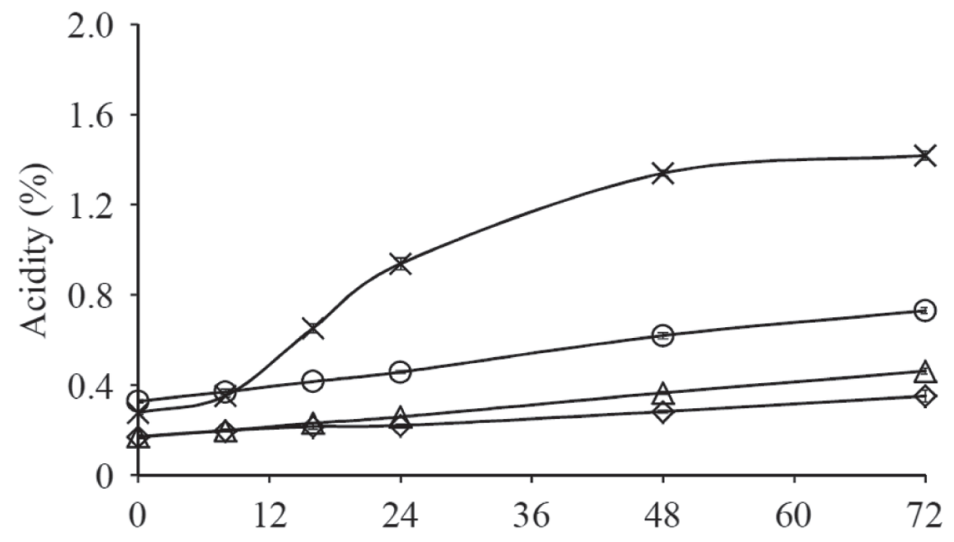

C

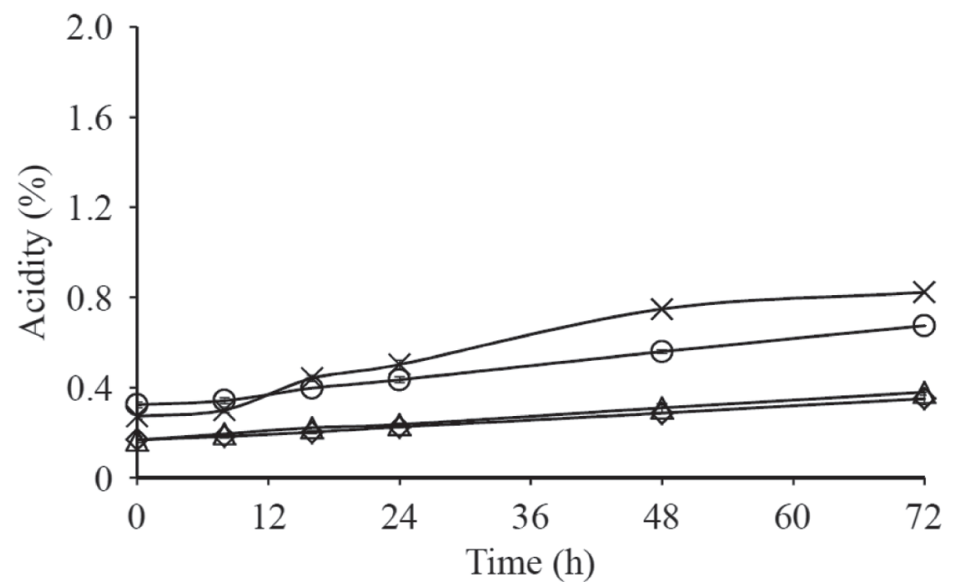

B

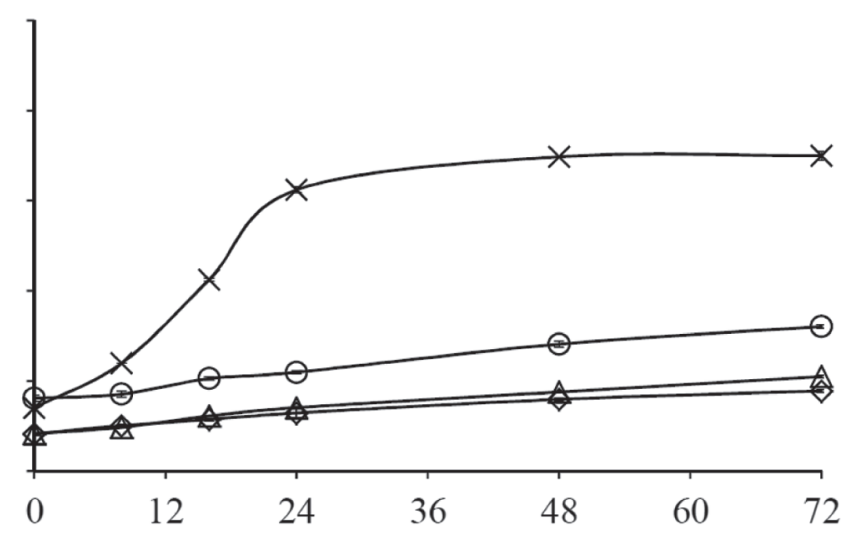

D

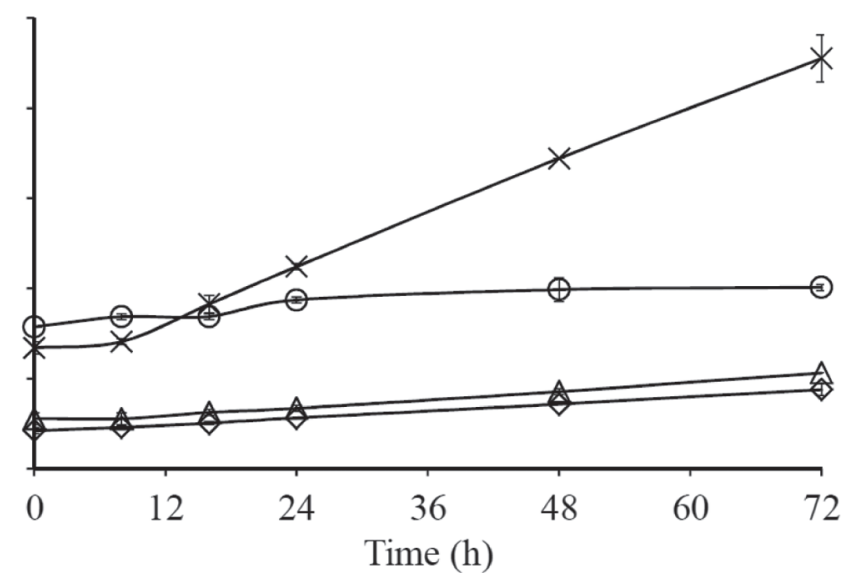

Figure 2. Changes in titratable acidity of culture solutions of Lactobacillus gasseri JCM $1131^{\mathrm{T}}$ (A), JCM 11046 (B), and JCM 11657 (C and D) in $8.3 \%$ (wt/vol) reconstituted skim milk (RSM) supplemented with casein, tryptone, or casamino acids. $\diamond=$ RSM; $\Delta=$ RSM supplemented with casein; $x=$ RSM supplemented with tryptone; $O=$ RSM supplemented with casamino acids. Casein, tryptone, and casamino acids were added at $1 \%$ (wt/vol; A, B, and C) or 3\% (wt/vol; D) each to RSM. Results are means of at least 2 independent determinations. Error bars represent standard deviations.

with $\mathrm{pH}$, titratable acidity, and viable cell count of the culture solutions of L. gasseri JCM $1131^{\mathrm{T}}$ in RSM. All treatments with the tested proteases excepting calf rennet $\left(3.7 \times 10^{7} \mathrm{cfu} / \mathrm{mL}\right.$ at $48 \mathrm{~h}$ incubation $)$ enhanced the growth of strain JCM $1131^{\mathrm{T}}$ to 1.5 to $5.9 \times 10^{8}$ $\mathrm{cfu} / \mathrm{mL}$ at $48 \mathrm{~h}$ incubation (Figure 4 ). In particular, the pepsin treatment and the joint treatment followed by trypsin and $\alpha$-chymotrypsin showed prominent growth-promoting effect $(\mathrm{pH} 3.9-4.0,1.0-1.3 \%$ acidity, and $3.5-5.9 \times 10^{8} \mathrm{cfu} / \mathrm{mL}$ at $48 \mathrm{~h}$ incubation). The maximum growth in the protease-treated RSM media was inferior to that in MRS broth at $12 \mathrm{~h}$ incubation. However, the cell number in the protease-treated RSM was maintained for 24 to $72 \mathrm{~h}$ incubation, whereas that in MRS broth decreased. Acid production in all of the media continued during the stationary phase on and after $24 \mathrm{~h}$ incubation, which was observed as a decrease of $\mathrm{pH}$ and increase of acidity in the culture solutions. The proteolytic effect of rennet was confirmed by card formation in the medium.

\section{Effect of Pepsinolysis on Growth of 43 Lactobacillus Strains in Milk}

Effect of peptide release by pepsinolysis on growth of 43 Lactobacillus strains listed in Table 1 was evaluated with changes in culture $\mathrm{pH}$ in WBM and a pepsintreated WBM medium. Growth (decrease in culture $\mathrm{pH}$ ) of all tested L. gasseri strains, each type strain of L. crispatus, L. gallinarum, and L. johnsonii, and a strain (305501) of L. acidophilus among the L. acidophilus complex members were drastically promoted by pepsinolysis of WBM (Figure 5 and Supplemental Table S1, http://dx.doi.org/10.3168/jds.2014-8860). 
A

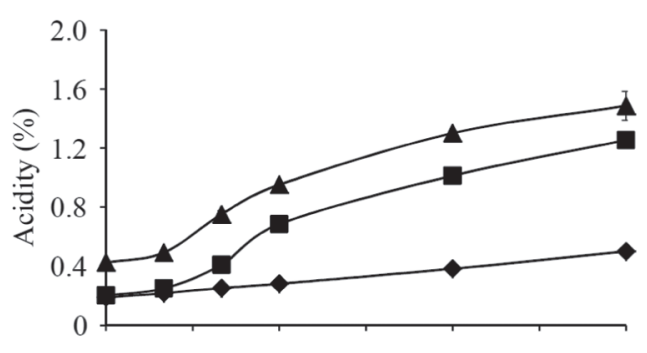

D

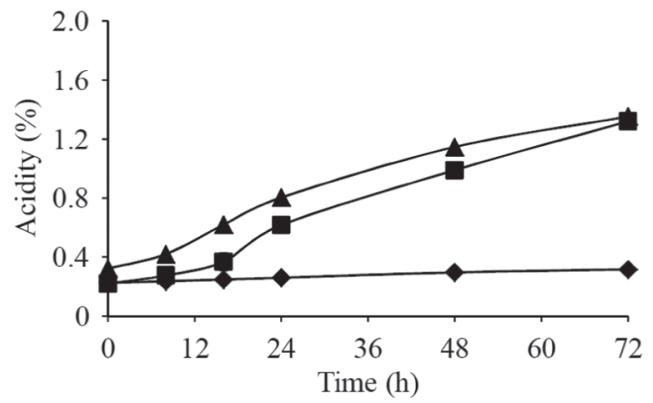

B

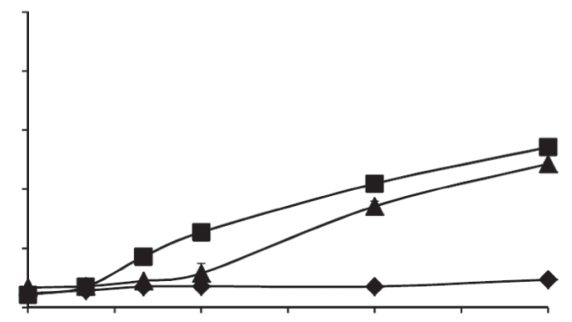

$\mathbf{E}$

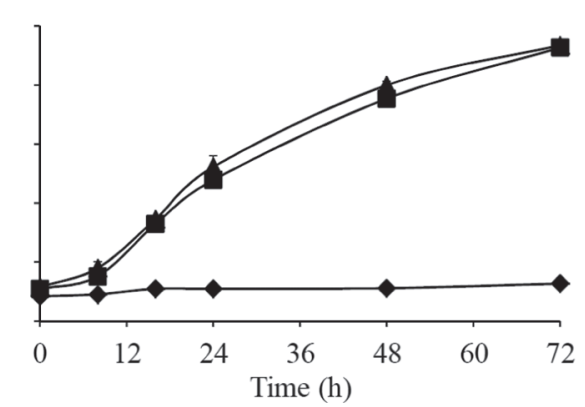

C

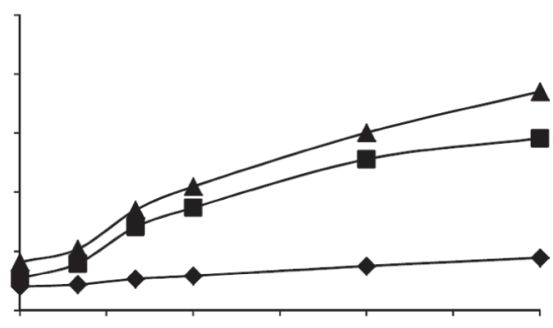

F

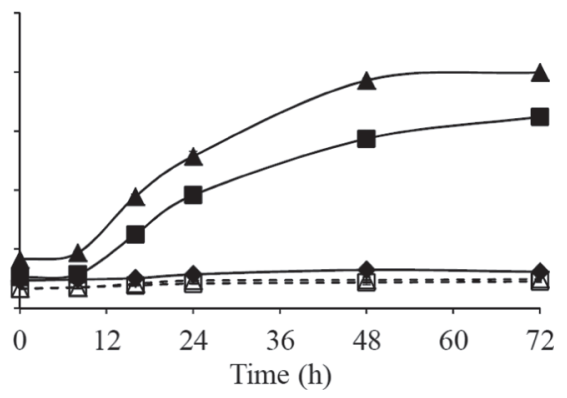

Figure 3. Changes in titratable acidity of culture solutions of Lactobacillus gasseri JCM $1131^{\mathrm{T}}$ in several milk-based media treated with digestive proteases. Whole bovine milk (A), human breast milk (B), 8.3\% (wt/vol) reconstituted skim milk (C), 21.5\% (wt/vol) reconstituted cheese whey (D), an acid whey medium (E), and a casein medium (F) were used as milk-based media. The acid whey medium and the casein medium were prepared by adding acid whey powder and casein, respectively, to modified DeMan, Rogosa, Sharpe (MRS) broth (MRSL-N) where peptone, Lab-Lemco, yeast extract, and glucose were absent from MRS broth and 2.0\% (wt/vol) lactose was added. based media; $\mathbf{\square}=$ milk-based media treated with pepsin; $\boldsymbol{\Lambda}=$ milk-based media treated with trypsin and $\alpha$-chymotrypsin following pepsin; $\square$ $=$ MRSL-N treated with pepsin; $\Delta=$ MRSL-N treated with trypsin and $\alpha$-chymotrypsin following pepsin. Results are means of 3 independent determinations. Error bars represent standard deviations.

However, the pepsinolysis had no or little effect on 3 strains of $L$. acidophilus and the type strain of $L$. amylovorus. Apart from the L. acidophilus complex members, the pepsinolysis showed the highest effect on Lactobacillus reuteri JCM $1112^{\mathrm{T}}$ and moderate effect on some strains such as Lactobacillus delbrueckii ssp. lactis 306701, Lactobacillus casei JCM 11302 and L-49, and Lactobacillus plantarum ssp. plantarum IFO 3070. In addition, temporal growth-promoting effect of the pepsinolysis was observed in some strains such as L. casei KCTC 3260 and NIAI L-14, and Lactobacillus paracasei ssp. paracasei ATCC 25598. Growth of the other tested strains was hardly promoted by the pepsinolysis. Interestingly, growth of L. delbrueckii ssp. bulgaricus JCM $1002^{\mathrm{T}}$ was significantly inhibited by the pepsinolysis.

\section{DISCUSSION}

Lactobacillus gasseri is empirically known to be poor growth in milk, which hurts its usability as a probiotic for the food industry. It had been previously reported that supplementation with yeast extract or proteose peptone rich in peptides improves growth of $L$. gasseri in milk (Avonts et al., 2004; Arakawa et al., 2008).
These reports suggested peptide requirement of L. gasseri for the growth in milk. In this study, growth of 3 strains of L. gasseri significantly increased by adding tryptone into MRS-N without any nitrogen sources (Figure 1 and Supplemental Figure S1, http://dx.doi. org/10.3168/jds.2014-8860). In contrast, addition of casein or casamino acids was ineffective for growth. Tryptone and casamino acids are casein hydrolysates consisting of peptides and free amino acids, respectively, and therefore their amino acid composition is approximately similar to casein. Although casamino acids should lack some amino acids such as tryptophan and cysteine by degradation with acid hydrolyzation, it had been already reported that simultaneous addition of 20 kinds of amino acids to a culture medium had hardly any effect on growth of a L. gasseri strain (Arakawa et al., 2008). These results indicate that $L$. gasseri definitely requires peptides, not proteins or free amino acids, among milk-derived nitrogen sources for growth. Peptide requirement of $L$. gasseri was further confirmed by individually adding the 3 nitrogen sources to RSM, resulting in the same conclusion that only tryptone enhanced growth of the 3 strains of $L$. gasseri (Figure 2 and Supplemental Figure S2, http://dx.doi. org/10.3168/jds.2014-8860). 
A

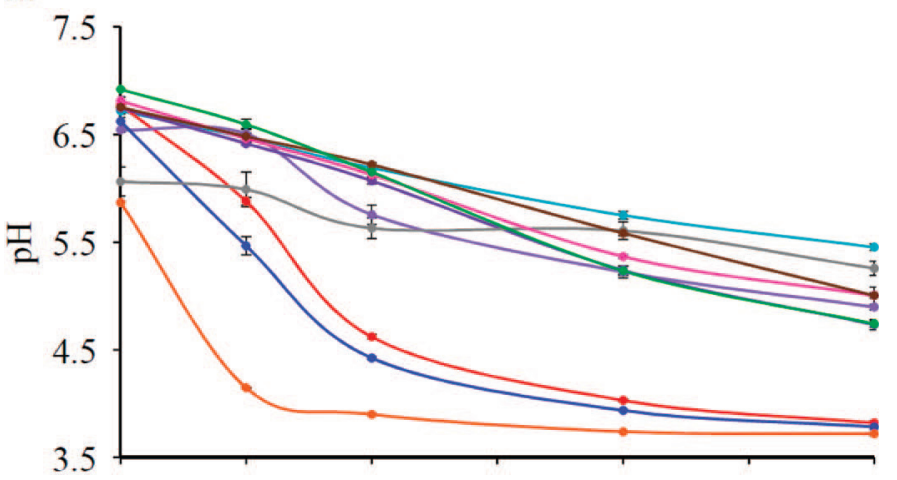

B

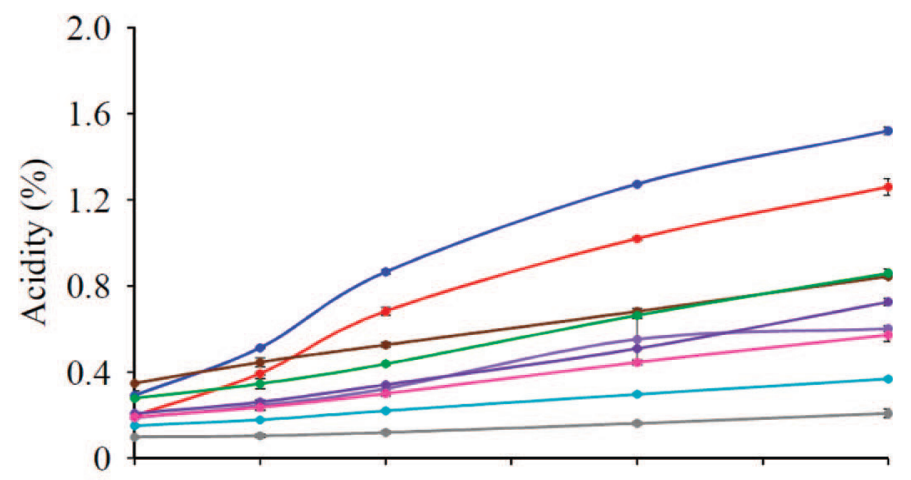

$\mathrm{C}$

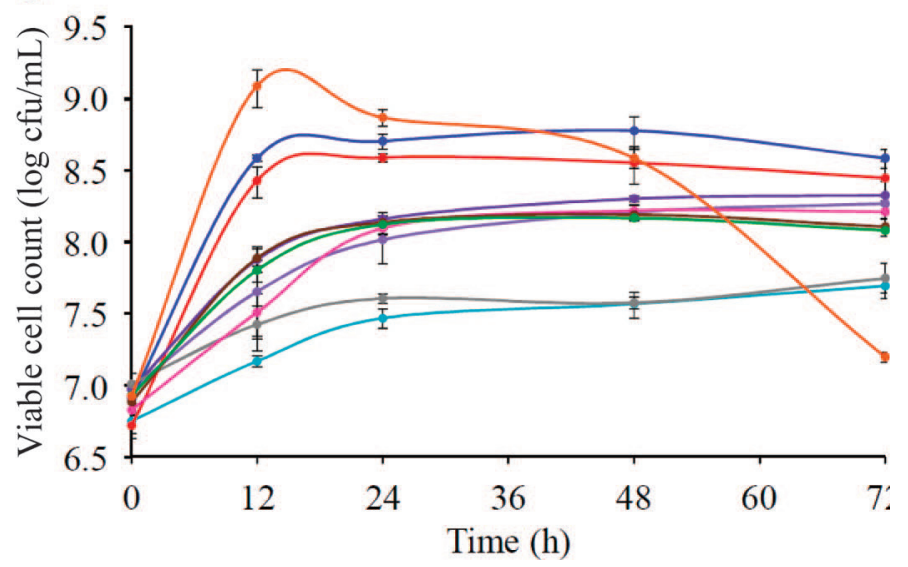

Figure 4. Changes in $\mathrm{pH}(\mathrm{A})$, titratable acidity (B), and viable cell count (C) of culture solutions of Lactobacillus gasseri JCM $1131^{\mathrm{T}}$ in $8.3 \%$ (wt/vol) reconstituted skim milk (RSM) treated with several food-grade proteases: pepsin (red), trypsin (violet), $\alpha$-chymotrypsin (purple), calf rennet (gray), ficin (pink), bromelain (brown), and papain (green). The other color lines show growth in undigested RSM (aqua), RSM treated with trypsin and $\alpha$-chymotrypsin following pepsin (blue), and MRS broth (orange). Results are means of 3 independent determinations. Error bars represent standard deviations.

In general, LAB initially degrade milk proteins into peptides with their cell-envelope proteases, and then take up the peptides via several transporter systems. After that, the peptides are further degraded into shorter peptides and amino acids with various intracellular peptidases for assimilation (Savijoki et al., 2006). Such a series of events should be a clue to explain why $L$. gasseri requires peptides, not proteins or free amino acids. A previous report shows that intracellular peptidase activity of $L$. gasseri strains was higher than that of L. acidophilus strains with better growth in milk (Masuda et al., 2005). Another report shows that L. gasseri strains released only a small amount of nonprotein nitrogen contents in the fermented milk, meaning weak activity of the cell-envelope proteases (Masuda et al., 2003b). So far, no valid cell-envelope protease genes have been identified in the genomes of $L$. gasseri strains such as ATCC $33323^{\mathrm{T}}$ (Azcarate-Peril et al., 2008). From the above information and the results in this study, it is suggested that the reason for peptide requirement of $L$. gasseri may be, because of its weak cell-envelope protease activity, unable to degrade the outside proteins enough, and its inadequate amino acid transporter systems unable to take up some essential amino acids. Inferior growth of strain JCM 11657 shown in Figures 1 and 2 and Supplemental Figures S1 and S2 (http://dx.doi.org/10.3168/jds.2014-8860) may be also due to the lesser capacities for degrading and transporting of nitrogen sources.

Incidentally, the 3 strains of $L$. gasseri grew well in the tryptone-added MRS-N, but the growth was inferior to that in MRS broth (Figure 1 and Supplemental Figure S1, http://dx.doi.org/10.3168/jds.2014-8860). This may be due to deficiency of some nucleotide precursors, vitamins, or minerals such as iron and zinc in the MRS-N-base by eliminating yeast extract and Lab-Lemco. Indeed, several reports showed that growth of some strains of the L. acidophilus complex members was improved by adding some of them to culture media (Elli et al., 1999; Ewe et al., 2010; Yadav et al., 2011).

Peptide requirement of $L$. gasseri was reconfirmed in 6 kinds of milk-based media treated with digestive proteases (Figure 3 and Supplemental Figure S3, http:// dx.doi.org/10.3168/jds.2014-8860). The tested strain, $\mathrm{JCM} 1131^{\mathrm{T}}$, grew well in every digested milk-based medium. This result means that it would be no matter which of casein and whey proteins is the origin of the peptides required by L. gasseri, although a specific growth-promoting peptide fragment(s) may be released from both proteins. Meanwhile, distinguishable growth curves of strain JCM $1131^{\mathrm{T}}$ were described by counting the viable cells in proteolyzed RSM media with various food-grade proteases (Figure 4). The growth variation indicates that it is rather important for L. gasseri what kind of protease is used to release nutritious peptides in the culture media. All proteases except calf rennet showed enough of the growth-promoting effect; in particular, that of pepsin was conspicuously high. Pepsin 

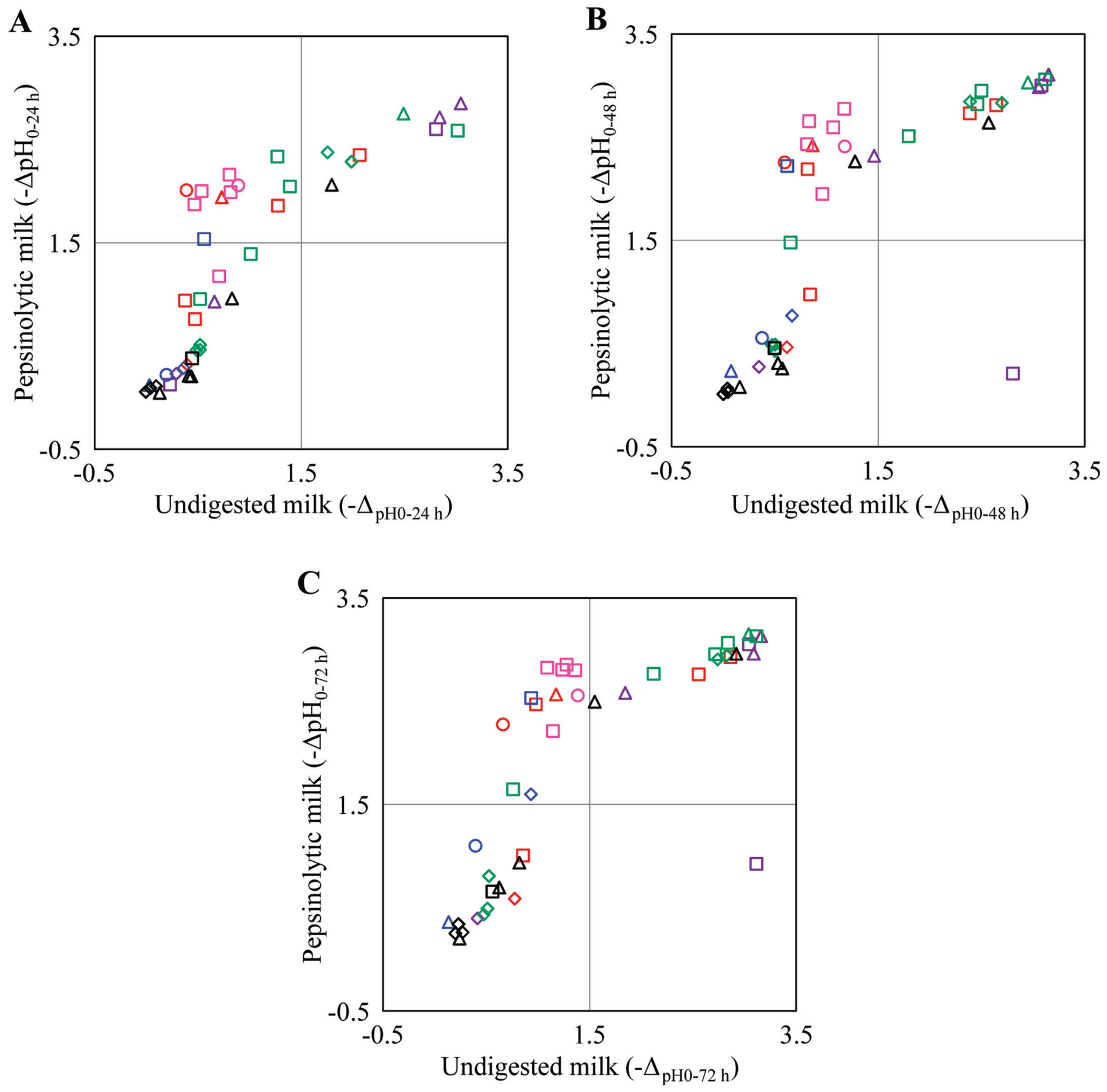

Figure 5. Maps showing decreases in culture $\mathrm{pH}$ of 43 Lactobacillus strains in undigested and pepsinolytic whole bovine milk. Decreases in culture $\mathrm{pH}$ were calculated for 24,48 , and $72 \mathrm{~h}$ (A, B, and C, respectively) of incubation. Red $\square=$ Lactobacillus acidophilus (4 strains); red $\diamond=$ Lactobacillus amylovorus (1 strain); red $\Delta=$ Lactobacillus crispatus (1 strain); red $\bigcirc=$ Lactobacillus gallinarum (1 strain); pink $\square=$ Lactobacillus gasseri (5 strains); pink $\bigcirc=$ Lactobacillus johnsonii (1 strain); purple $\square=$ Lactobacillus delbrueckii ssp. bulgaricus (2 strains); purple $\diamond=$ Lactobacillus delbrueckii ssp. delbrueckii (1 strain); purple $\Delta=$ Lactobacillus delbrueckii ssp. lactis (3 strains); blue $\square=$ Lactobacillus reuteri (1 strain); blue $\diamond=$ Lactobacillus fermentum (1 strain); blue $\Delta=$ Lactobacillus oris ( 1 strain); blue $\bigcirc=$ Lactobacillus vaginalis (1 strain); green $\square=$ Lactobacillus casei (5 strains); green $\diamond=$ Lactobacillus paracasei ssp. paracasei (5 strains); green $\Delta=$ Lactobacillus rhamnosus (1 strain); black $\square=$ Lactobacillus salivarius (1 strain); black $\diamond=$ Lactobacillus brevis (3 strains); black $\Delta=$ Lactobacillus plantarum ssp. plantarum (5 strains). Results are means of at least 2 independent determinations. 
has a broad-spectrum proteolytic capacity to produce smaller peptide fragments compared with the other tested proteases. This suggests that comparatively small peptides may be suitable as nitrogen sources for L. gasseri in milk-based media. The suggestion seems to be supported by the results that the joint treatment with trypsin and $\alpha$-chymotrypsin following pepsin yielded better growth of strain JCM $1131^{\mathrm{T}}$ than that with pepsin alone in all milk-based media excepting HBM (Figures 3 and 4 and Supplemental Figure S3, http://dx.doi.org/10.3168/jds.2014-8860). In addition, the suggestion is consistent with the result that no growth-promoting effect was observed in RSM treated with calf rennet just producing 2 large peptides, para$\kappa$-casein and glycomacropeptide, from $\kappa$-casein. At present, examinations for identification of peptide fragments suitable to grow L. gasseri and determination of their molecular weight range are in progress.

The growth-promoting effect of pepsinolysis was evaluated in 43 strains of lactobacilli including $L$. gasseri (Figure 5 and Supplemental Table S1, http:// dx.doi.org/10.3168/jds.2014-8860). The pepsinolysis in WBM showed the high effect especially on all tested strains of $L$. gasseri and the type strains of $L$. crispatus, L. gallinarum, L. johnsonii, and L. reuteri. Any of these species has been frequently detected in the GI tract and feces of humans and animals. This coincidence should be an in vitro evidence that these predominant lactobacilli would take in peptides released from ingested milk by peptic digestion in the GI tract; in other words, milk would be a pre-prebiotic nitrogen source supplying nutritious peptides to the enteric lactobacilli in the GI tract, particularly of breast-fed infants. Other strains such as L. delbrueckii ssp. lactis 306701, L. casei JCM 11302 and L-49, and L. plantarum ssp. plantarum IFO 3070 also benefited by the proteolysis. Previously, a few research groups had reported that supplementation of media with pepsinolytic casein and whey protein enhanced growth of L. acidophilus, L. rhamnosus, and L. plantarum strains (Kafley et al., 2010; Robitaille and Champagne, 2014). In other reports, it had been shown that casein fragments digested by proteases except pepsin increase growth of L. acidophilus strains (Saxena et al., 1994; Masuda et al., 2003a). However, it had never been reported before this study that so many Lactobacillus strains were growth-promoted by enzymatic proteolysis in milk.

Among the tested 43 strains, only L. delbrueckii ssp. bulgaricus JCM $1002^{\mathrm{T}}$ was significantly growthinhibited by pepsinolysis of milk proteins (Figure 5 and Supplemental Table S1, http://dx.doi.org/10.3168/ jds.2014-8860). This result might be related to its (already known) exclusive cell-envelope protease, PrtB, to release comparatively large peptides (Germond et al., 2003) and its peculiar peptide transport system depending on only 2 oligopeptide transporters, Opp (Peltoniemi et al., 2002; van de Guchte et al., 2006). That is to say that peptides released by the pepsinolysis might be too small for the strain without any definite di-tripeptide transporter genes to import into the cells.

This is the first report showing that peptide requirement of L. gasseri and efficacy of pepsin treatment on growth in milk-based media. Furthermore, we described here that pepsinolysis promoted growth of the related lactobacilli as well as L. gasseri in milk. This study would contribute to increasing the usability of $L$. gasseri and the relatives and developing new fermented dairy products using them as probiotics.

\section{ACKNOWLEDGMENTS}

We are grateful to a volunteer who provided breast milk and the kind researchers at Godo Shusei Co. for the provision of bromelain and papain. We also thank Y. Omori, H. Takeda, C. Hano, and H. Mineyuki (Faculty of Agriculture, Okayama University) for their assistance with several measurements. This work was funded by a research grant of the Institute for Fermentation, Osaka, to K. Arakawa and the Grant-in-Aid for Young Scientists (B; no. 26870393) from the Japan Society for the Promotion of Science to K. Arakawa.

\section{REFERENCES}

Arakawa, K., Y. Kawai, K. Fujitani, J. Nishimura, H. Kitazawa, K. Komine, K. Kai, and T. Saito. 2008. Bacteriocin production of probiotic Lactobacillus gasseri LA39 isolated from human feces in milk-based media. Anim. Sci. J. 79:634-640.

Arakawa, K., Y. Kawai, H. Iioka, M. Tanioka, J. Nishimura, H. Kitazawa, K. Tsurumi, and T. Saito. 2009. Effects of gassericins A and $\mathrm{T}$, bacteriocins produced by Lactobacillus gasseri, with glycine on custard cream preservation. J. Dairy Sci. 92:2365-2372.

Arakawa, K., Y. Kawai, Y. Ito, K. Nakamura, T. Chujo, J. Nishimura, H. Kitazawa, and T. Saito. 2010. HPLC purification and re-evaluation of chemical identity of two circular bacteriocins, gassericin A and reutericin 6. Lett. Appl. Microbiol. 50:406-411.

Avonts, L., E. Van Uytven, and L. De Vuyst. 2004. Cell growth and bacteriocin production of probiotic Lactobacillus strains in different media. Int. Dairy J. 14:947-955.

Azcarate-Peril, M. A., E. Altermann, Y. J. Goh, R. Tallon, R. B. Sanozky-Dawes, E. A. Pfeiler, S. O'Flaherty, B. L. Buck, A. Dobson, T. Duong, M. J. Miller, R. Barrangou, and T. R. Klaenhammer. 2008. Analysis of the genome sequence of Lactobacillus gasseri ATCC 33323 reveals the molecular basis of an autochthonous intestinal organism. Appl. Environ. Microbiol. 74:4610-4625.

Bogovic-Matijasić, B., and I. Rogelj. 2000. Lactobacillus K7-A new candidate for a probiotic strain. Food Technol. Biotechnol. 38:113-119.

Bogovic-Matijasić, B., I. Rogelj, I. F. Nes, and H. Holo. 1998. Isolation and characterization of two bacteriocins of Lactobacillus acidophilus LF221. Appl. Microbiol. Biotechnol. 49:606-612.

Dal Bello, F., and C. Hertel. 2006. Oral cavity as natural reservoir for intestinal lactobacilli. Syst. Appl. Microbiol. 29:69-76.

Elli, M., R. Zink, R. Reniero, and L. Morelli. 1999. Growth requirements of Lactobacillus johnsonii in skim and UHT milk. Int. Dairy J. 9:507-513 
Ewe, J. A., W. N. Wan-Abdullah, and M. T. Liong. 2010. Viability and growth characteristics of Lactobacillus in soymilk supplemented with B-vitamins. Int. J. Food Sci. Nutr. 61:87-107.

Fujisawa, T., Y. Benno, T. Yaeshima, and T. Mitsuoka. 1992. Taxonomic study of the Lactobacillus acidophilus group, with recognition of Lactobacillus gallinarum sp. nov. and Lactobacillus johnsonii sp. nov. and synonymy of Lactobacillus acidophilus group A3 (Johnson et al. 1980) with the type strain of Lactobacillus amylovorus (Nakamura 1981). Int. J. Syst. Bacteriol. 42:487-491.

Germond, J. E., M. Delley, C. Gilbert, and D. Atlan. 2003. Determination of the domain of the Lactobacillus delbrueckii ssp. bulgaricus cell surface proteinase PrtB involved in attachment to the cell wall after heterologous expression of the prtB gene in Lactococcus lactis. Appl. Environ. Microbiol. 69:3377-3384.

Itoh, T., Y. Fujimoto, Y. Kawai, T. Toba, and T. Saito. 1995. Inhibition of food-borne pathogenic bacteria by bacteriocins from Lactobacillus gasseri. Lett. Appl. Microbiol. 21:137-141.

Johnson, J. L., C. F. Phelps, C. S. Cummins, J. London, and F. Gasser. 1980. Taxonomy of the Lactobacillus acidophilus Group. Int. J. Syst. Bacteriol. 30:53-68.

Kadooka, Y., M. Sato, K. Imaizumi, A. Ogawa, K. Ikuyama, Y. Akai, M. Okano, M. Kagoshima, and T. Tsuchida. 2010. Regulation of abdominal adiposity by probiotics (Lactobacillus gasseri SBT2055) in adults with obese tendencies in a randomized controlled trial. Eur. J. Clin. Nutr. 64:636-643.

Kafley, S., W. S. Kim, H. Kumura, and K. Shimazaki. 2010. Growth performance of whey protein hydrolysates in the media on different strains of probiotic bacteria. Milchwissenschaft 65:245-248.

Kawai, Y., T. Saito, H. Kitazawa, and T. Itoh. 1998. Gassericin A; an uncommon cyclic bacteriocin produced by Lactobacillus gasseri LA39 linked at $N$ - and $C$-terminal ends. Biosci. Biotechnol. Biochem. 62:2438-2440.

Kawai, Y., T. Saito, J. Uemura, and T. Itoh. 1997. Rapid detection method for bacteriocin and distribution of bacteriocin-producing strains in Lactobacillus acidophilus group lactic acid bacteria isolated from human feces. Biosci. Biotechnol. Biochem. 61:179-182.

Kawai, Y., B. Saitoh, O. Takahashi, H. Kitazawa, T. Saito, H. Nakajima, and T. Itoh. 2000. Primary amino acid and DNA sequences of gassericin T, a lactacin F-family bacteriocin produced by Lactobacillus gasseri SBT2055. Biosci. Biotechnol. Biochem. 64:22012208.

Lamont, R. F., J. D. Sobel, R. A. Akins, S. S. Hassan, T. Chaiworapongsa, J. P. Kusanovic, and R. Romero. 2011. The vaginal microbiome: New information about genital tract flora using molecular based techniques. BJOG 118:533-549.

Majhenic, A. C., K. Venema, G. E. Allison, B. B. Matijasić, I. Rogelj, and T. R. Klaenhammer. 2004. DNA analysis of the genes encoding acidocin LF221 A and acidocin LF221 B, two bacteriocins produced by Lactobacillus gasseri LF221. Appl. Microbiol. Biotechnol. 63:705-714.

Martín, R., S. Langa, C. Reviriego, E. Jimínez, M. L. Marín, J. Xaus, L. Fernández, and J. M. Rodríguez. 2003. Human milk is a source of lactic acid bacteria for the infant gut. J. Pediatr. 143:754-758.

Masuda, T., A. Hidaka, N. Kondo, T. Ura, and T. Itoh. 2005. Intracellular enzyme activities and autolytic properties of Lactobacillus acidophilus and Lactobacillus gasseri. Food Sci. Technol. Res. 11:328-331.

Masuda, T., R. Taguchi, T. Kabuki, H. Nakajima, and T. Itoh. 2003a. Improvement of the growth of Lactobacillus acidophilus in milk by addition of enzymatically digested casein. Milchwissenschaft $58: 124-127$

Masuda, T., R. Taguchi, T. Kabuki, H. Nakajima, and T. Itoh. 2003b. Growth profile of Lactobacillus acidophilus group lactic acid bacteria in milk relating to their proteolytic activity. Milchwissenschaft 58:366-370.

Matsumiya, Y., N. Kato, K. Watanabe, and H. Kato. 2002. Molecular epidemiological study of vertical transmission of vaginal Lactobacillus species from mothers to newborn infants in Japanese, by arbitrarily primed polymerase chain reaction. J. Infect. Chemother. 8:43-49.

Nakamura, K., K. Arakawa, Y. Kawai, N. Yasuta, T. Chujo, M. Watanabe, H. Iioka, M. Tanioka, J. Nishimura, H. Kitazawa, K. Tsurumi, and T. Saito. 2013. Food preservative potential of gassericin Acontaining concentrate prepared from a cheese whey culture supernatant from Lactobacillus gasseri LA39. Anim. Sci. J. 84:144-149.

Peltoniemi, K., E. Vesanto, and A. Palva. 2002. Genetic characterization of an oligopeptide transport system from Lactobacillus delbrueckii ssp. bulgaricus. Arch. Microbiol. 177:457-467.

Reuter, G. 2001. The Lactobacillus and Bifidobacterium microflora of the human intestine: Composition and succession. Curr. Issues Intest. Microbiol. 2:43-53.

Robitaille, G., and C. P. Champagne. 2014. Growth-promoting effects of pepsin- and trypsin-treated caseinomacropeptide from bovine milk on probiotics. J. Dairy Res. 81:319-324.

Savijoki, K., H. Ingmer, and P. Varmanen. 2006. Proteolytic systems of lactic acid bacteria. Appl. Microbiol. Biotechnol. 71:394-406.

Saxena, S. N., B. K. Mital, and S. K. Garg. 1994. Effect of casitone and fructose on the growth of Lactobacillus acidophilus and its survival during storage. Int. J. Food Microbiol. 21:271-276.

Selle, K., and T. R. Klaenhammer. 2013. Genomic and phenotypic evidence for probiotic influences of Lactobacillus gasseri on human health. FEMS Microbiol. Rev. 37:915-935.

Toba, T., E. Yoshioka, and T. Itoh. 1991. Potential of Lactobacillus gasseri isolated from infant faeces to produce bacteriocin. Lett. Appl. Microbiol. 12:228-231.

Treven, P., K. Turkova, A. Trmčić, T. Obermajer, I. Rogelj, and B. B. Matijašić. 2013. Detection and quantification of probiotic strain Lactobacillus gasseri K7 in faecal samples by targeting bacteriocin genes. Folia Microbiol. (Praha) 58:623-630.

van de Guchte, M., S. Penaud, C. Grimaldi, V. Barbe, K. Bryson, P. Nicolas, C. Robert, S. Oztas, S. Mangenot, A. Couloux, V. Loux, R. Dervyn, R. Bossy, A. Bolotin, J. M. Batto, T. Walunas, J. F. Gibrat, P. Bessières, J. Weissenbach, S. D. Ehrlich, and E. Maguin. 2006. The complete genome sequence of Lactobacillus bulgaricus reveals extensive and ongoing reductive evolution. Proc. Natl. Acad. Sci. USA 103:9274-9279.

Wall, R., G. Fitzgerald, S. Hussey, T. Ryan, B. Murphy, P. Ross, and C. Stanton. 2007. Genomic diversity of cultivable Lactobacillus populations residing in the neonatal and adult gastrointestinal tract. FEMS Microbiol. Ecol. 59:127-137.

Yadav, S., S. Gite, S. Nilegaonkar, and V. Agte. 2011. Effect of supplementation of micronutrients and phytochemicals to fructooligosaccharides on growth response of probiotics and E. coli. Biofactors $37: 58-64$.

Yasuta, N., K. Arakawa, Y. Kawai, T. Chujo, K. Nakamura, H. Suzuki, Y. Ito, J. Nishimura, Y. Makino, S. Shigenobu, and T. Saito. 2014. Genetic and biochemical evidence for gassericin T production from Lactobacillus gasseri LA158. Milk Sci. 63:9-17. 